Article

\title{
An Unusual Stress Metabolite from a Hydrothermal Vent Fungus Aspergillus sp. WU 243 Induced by Cobalt
}

\author{
Chihong Ding ${ }^{1}$, Xiaodan Wu ${ }^{1}$, Bibi Nazia Auckloo ${ }^{1}$, Chen-Tung Arthur Chen ${ }^{1,2}$, Ying Ye ${ }^{1}$, \\ Kuiwu Wang ${ }^{3}$ and Bin $\mathrm{Wu}^{1, *}$
}

Received: 16 December 2015; Accepted: 14 January 2016; Published: 16 January 2016

Academic Editor: Maxim L. Kuznetsov

1 Ocean College, Zhejiang University, Hangzhou 310058, China; dingchihong@163.com (C.D.);

wxd_zju@163.com (X.W.); naz22ia@hotmail.com (B.N.A.); ctchen@faculty.nsysu.edu.tw (C.-T.A.C.);

gsyeying@zju.edu.cn (Y.Y.)

2 Institute of Marine Geology and Chemistry, National Sun Yat-sen University, Kaohsiung 80424, Taiwan

3 Department of Applied Chemistry, Zhejiang Gongshang University, Hangzhou 310058, China;

wkwnpc@zjgsu.edu.cn

* Correspondence: wubin@zju.edu.cn; Tel./Fax: +86-571-8820-8540

\begin{abstract}
A novel hybrid polyketide-terpenoid, aspergstressin (1), possessing a unique fused polycyclic structure, was induced from culture broth of strain Aspergillus sp. WU 243 by cobalt ion stimulation. The strain was isolated from the digestive gland of Xenograpsus testudinatus, a unique type of crab which dwells in the Kueishantao hydrothermal vents off Taiwan. The chemical structure and relative configuration of the stress metabolite were established by spectroscopic means. Aspergillus sp. WU 243 produced aspergstressin (1) only under cobalt stressed culture conditions. The results show that stress-driven discovery of new natural products from hydrothermal vent fungi is an effective strategy to unveil the untapped reservoir of small molecules from species found in the hydrothermal vent environment.
\end{abstract}

Keywords: marine fungi; metal-stress; hydrothermal vent; marine natural products

\section{Introduction}

Marine hydrothermal vent microorganisms adapt and respond rapidly to changes in the availability and concentrations of metals within their harsh and dynamic environment $[1,2]$. Marine organisms, living in a biologically competitive and stressful habitat, are of great interest as new promising sources of biologically active products [3-5]. Contrary to the perception that metals hinder secondary metabolite production, recent studies have showed that metals can induce or enhance the synthesis of possibly potent and medically relevant metabolites [5-7]. Arousing sleeping genes or producing structures with stereochemical features which facilitate metal complexation and their transportation in biological systems may account for the mechanisms behind the metal-induced metabolite phenomenon $[7,8]$.

In this study, the metal-stress method was applied on a marine fungus strain isolated from the digestive gland of Xenograpsus testudinatus, which was collected from a Kueishantao Island hydrothermal vent in Taiwan. The strain was identified as Aspergillus sp. by comparing $18 \mathrm{~S}$ ribosomal RNA genes with database information. As a result, a new hybrid polyketide-terpenoid named aspergstressin (1) induced by cobalt ion was identified as the new stress metabolite. 


\section{Results and Discussion}

\subsection{Identification of Strain WU 243}

Strain WU 243 were isolated from the digestive gland of Xenograpsus testudinatus, a unique type of arthropod which inhabits in the Kueishantao hydrothermal vents off northeast Taiwan. The strain was cultured on PD agar (PDA) medium and grew as white mycelium covered with deep green spores (Figure 1). According to the morphological criteria for identification, Aspergillus and Penicillium were both potential candidates.

The sequences of the 18S rRNA genes for strain WU 243 comprised 593 nucleotides. The highest sequence similarity (100\%) was observed for the strains Aspergillus sp. BMP3039 18 S ribosomal RNA gene, internal transcribed spacer $1,5.8 S$ ribosomal RNA gene, internal transcribed spacer 2, and $28 \mathrm{~S}$ ribosomal RNA gene region and Aspergillus versicolor strain LTBF 011-1 18S ribosomal RNA gene, partial sequence; internal transcribed spacer 1, 5.8S ribosomal RNA gene, and internal transcribed spacer 2, complete sequence; and 28S ribosomal RNA gene, partial sequence. From the above results, strain WU 243 was classified as an Aspergillus sp.

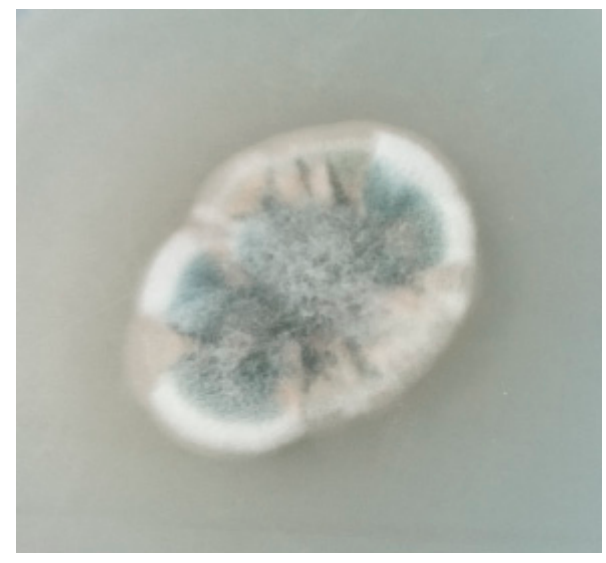

Figure 1. Aspergillus sp. strain WU 243, agar colony on PDA (PD agar) medium after 7 days of incubation at $24^{\circ} \mathrm{C}$.

\subsection{Metabolic Profiles of the Strain WU 243 after Metal-Stress Application and Optimization of Stress Fermentation}

Cultivation experiments of strain WU 243 were carried out in potato dextrose broth (PDB) media under static conditions. The strain was tested for its susceptibility to cadmium, zinc, cobalt, and nickel, and results showed that only cobalt induced the production of stress metabolites. The change in metabolic pattern after cobalt ion induction was verified by setting up one medium without fungus as a blank control, one medium without ions and six sets of media with different ion concentrations (6 $\mathrm{mM}$ to $10 \mathrm{mM})$. Mycelium and culture broth were separated by a gauze filter and the culture broth was extracted with ethyl acetate. Results showed that a new peak (compound 1) appeared, which was almost invisible in the non-metal treated fungal extract. Among the different concentrations, the concentration of $6 \mathrm{mM}$ cobalt was observed as the most effective (Figure 2). More interestingly, the production of the normal main product appearing at $22.5 \mathrm{~min}$, which was purified and identified as the known compound ditryptophenaline [9] (Figure 3), was drastically reduced under metal stress. When the concentration of cobalt reached $9 \mathrm{mM}$, the main product at $22.5 \mathrm{~min}$ almost ceased to secrete, and stress metabolites were overwhelmingly the major products in the extract. Three new peaks (retention times: 20.5, 24.25 and $26.75 \mathrm{~min}$, respectively) in addition to compound 1 were found in traces of the cobalt-containing cultures. These compounds were purified by preparative HPLC and identified as the known compounds cyclo-(L-tryptophyl-L-phenylalanyl) [10], cordyol C [11] and 
sydonic acid [12] (Figure 3). The NMR data and assignments of the known compounds are available in the Supplementary Materials.

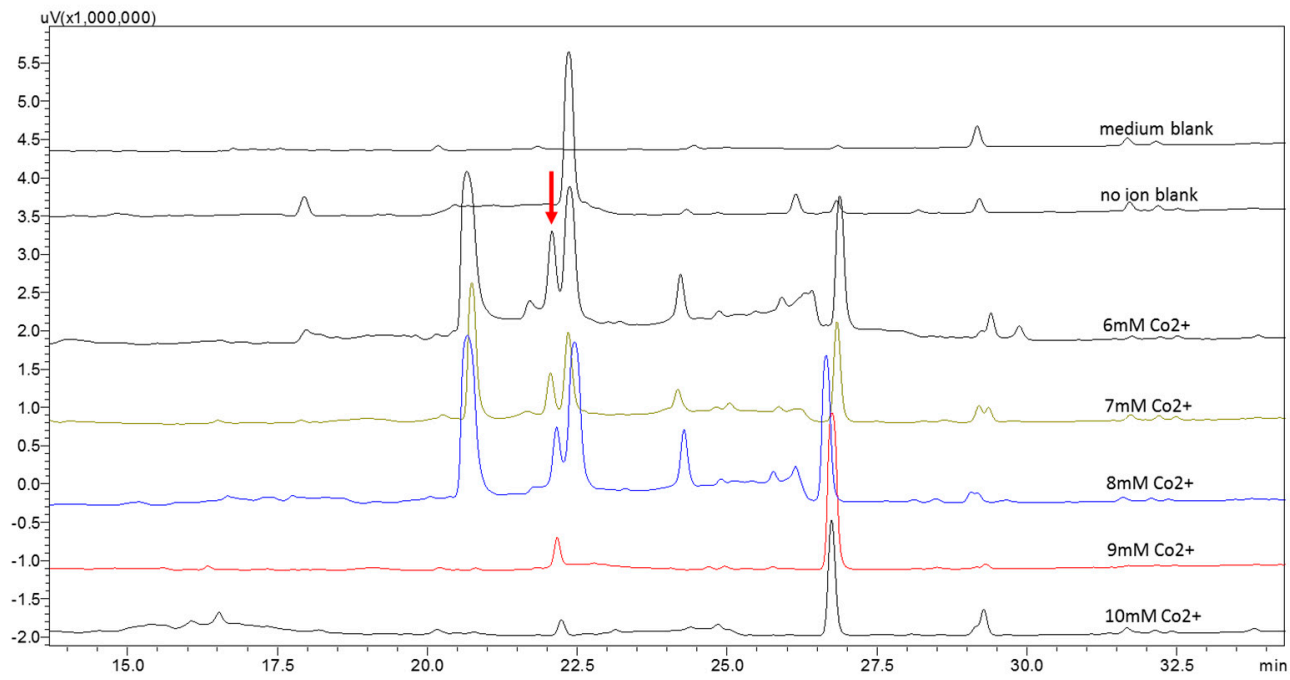

Figure 2. Metabolic profile of strain WU 243 by HPLC analysis: blank control and six sets of different ion concentrations.<smiles>O=C1N[C@H](Cc2ccccc2)C(=O)N2C[C@]3(O)c4ccccc4N[C@H]3C[C@H]12</smiles>

ditryptophenaline<smiles>Cc1cc(O)cc(Oc2cc(C)cc(O)c2O)c1</smiles>

cordyol C

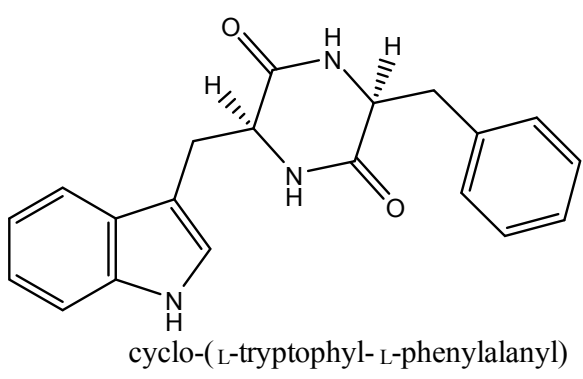<smiles>CC(C)CCC[C@](C)(O)c1ccc(C(=O)O)cc1O</smiles>

sydonic acid

Figure 3. Structures of known compounds.

The metal-stress experiment was first carried out by setting four cobalt ion concentrations of 0,5 , 10 , and $20 \mathrm{mM}$, respectively. The strain was cultured for 14 days at $24^{\circ} \mathrm{C}$ under static conditions. It was observed that the growth of the strain was inhibited in $20 \mathrm{mM}$ cobalt ion medium. The mycelium was removed and culture broth was extracted with ethyl acetate in equal volume. The HPLC profile of each extract showed the fungal metabolic response to ion stimulation when the cobalt ion concentration was up to $5 \mathrm{mM}$. When the cobalt ion concentration was $10 \mathrm{mM}$, few secondary metabolites were detected.

In order to improve the stress metabolite yield, the conditions for stress fermentation have been optimized. Since cobalt ions are toxic to fungi, the growth rate was significantly inhibited when the cobalt ion concentration reached $5 \mathrm{mM}$ in PDA medium (Figure 4). However, according to the primary experimental results, stress products could be detected only when the cobalt ion concentration was up to $5 \mathrm{mM}$. Therefore, enhancing the production of the stress metabolites in the range of ion 
concentrations with good growth rate was important. The fungus was treated with five different ion concentrations from $6 \mathrm{mM}$ to $10 \mathrm{mM}$. The HPLC profile of each extract revealed the peak area of stress compound 1 was maximized at $6 \mathrm{mM}$ cobalt ion concentration and it decreased with increasing ion concentrations. Hence, $6 \mathrm{mM}$ cobalt ion concentration was selected for large scale stress fermentations.

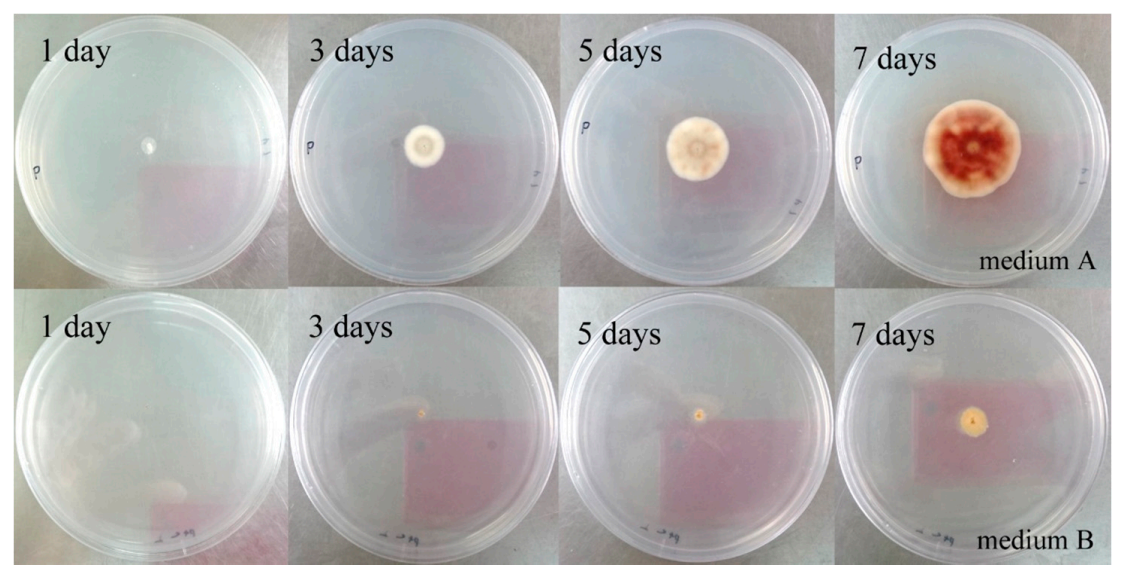

Figure 4. Fungal colonies in medium A (agar plates with PDA) and medium B (agar platess with PDA and $5 \mathrm{mM} \mathrm{CoCl}_{2}$ ) after 1, 3, 5 and 7 days of incubation.

In order to accelerate the growth of the fungus and the accumulation of metabolites, the fermentation temperature was raised to $28^{\circ} \mathrm{C}$ and the duration of cultivation was prolonged to 18 days. Twenty L of zymotic fluid were placed in flasks of two sizes, $500 \mathrm{~mL}$ and $5 \mathrm{~L}$, under static conditions.

\subsection{Structural Elucidation}

After large scale fermentation, the culture broth was collected and extracted with ethyl acetate. The extracts of the broth of strain WU 243 were then subjected to column chromatography and preparative HPLC to obtain purified compound 1 (Figure 5).

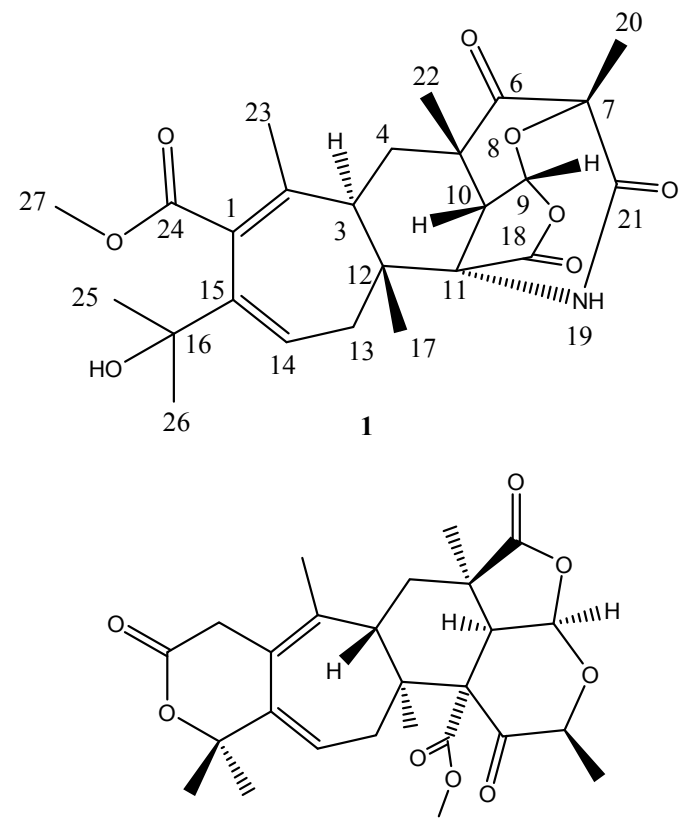

berkeleyacetals A

Figure 5. Structures of compound 1 and berkeleyacetal A [13]. 
Compound 1 was isolated as a white powder. The molecular formula $\mathrm{C}_{25} \mathrm{H}_{31} \mathrm{NO}_{8}$ was determined by analysis of the HR-TOF-MS data. The formula was supported by the ${ }^{13} \mathrm{C}-\mathrm{NMR}$ data, which indicated 11 degrees of unsaturation. The NMR data (Table 1) of compound 1 were similar to those of the berkeleyacetals analogues [13]. These molecules contain two distinct domains, a tricyclic hydrocarbon and a $\delta$-lactone ring, connected by a seven member ring [13]. The skeleton of fused polycyclic system contains a seven membered ring, a six membered ring, a five membered lactone ring and six membered ketonic ether ring. The 25 carbon signals comprised seven methyls $\left(\delta_{C} 16.5,26.4,26.8,27.8,30.7,32.3\right.$ and 54.7), two methylenes $\left(\delta_{C} 32.4,40.3\right)$ and three methines $\left(\delta_{C} 44.8,45.2\right.$ and 100.0). A comparison between the DEPT 135 and ${ }^{13}$ C-NMR spectra revealed five quaternary carbons $\left(\delta_{C} 48.0,51.7,56.6,81.8\right.$ and 85.6), two sets of double bonds (127.9 and 131.5, 139.8 and 140.9) and four carbonyls $\left(\delta_{C} 211.2,173.2\right.$, 174.3 and 173.2). The ${ }^{13} \mathrm{C}-\mathrm{NMR}$ spectrum of 1 showed the presence of 14 signals for the hydrocarbon domain, including a tricyclic basic skeleton, with the remaining 11 resonances corresponding to a cyclohepta-1,3-diene with a dimethyl carbinol moiety and a methoxycarbonyl group. When compared to the NMR data of berkeleyacetal A [13], isolated from the fungus Penicillium sp. growing in Berkeley Pit Lake, compound $\mathbf{1}$ showed similar chemical shifts of the main fused polycyclic skeleton and the seven membered ring unit. However, 1D and 2D NMR analysis revealed that the substructure of tricyclic hydrocarbon and the units attached on it were less similar to berkeleyacetal A. In the ${ }^{1} \mathrm{H}-{ }^{1} \mathrm{H}$ COSY spectrum of compound 1 (Figure 6), the olefin proton at $\delta_{\mathrm{H}} 6.39(\mathrm{dd}, J=8.0,5.2 \mathrm{~Hz}$, $\mathrm{H}-14)$ was coupled with two methylene protons at $\delta_{\mathrm{H}} 2.51(\mathrm{dd}, J=13.2,8.0 \mathrm{~Hz}, \mathrm{H}-13 \alpha)$ and 1.78 $(\mathrm{dd}, J=13.2,5.2 \mathrm{~Hz}, \mathrm{H}-13 \beta)$, and the methine protons at $\delta_{\mathrm{H}} 2.06(\mathrm{dd}, J=13.5,2.1 \mathrm{~Hz}, \mathrm{H}-3)$ were coupled with two methylene protons at $\delta_{\mathrm{H}} 1.50(\mathrm{t}, J=13.5 \mathrm{~Hz}, \mathrm{H}-4 \alpha)$ and $2.39(\mathrm{dd}, J=13.6,2.6 \mathrm{~Hz}$, $\mathrm{H}-4 \beta)$. The methine proton at $\delta_{\mathrm{H}} 6.09(\mathrm{~d}, J=7.1 \mathrm{~Hz}, \mathrm{H}-9)$ exhibited cross peaks with methine proton at $\delta_{\mathrm{H}} 3.27(\mathrm{~d}, J=7.1 \mathrm{~Hz}, \mathrm{H}-10)$ in the COSY spectrum of 1 . The sequence and linkages of four ring system of $\mathrm{H}-3 / \mathrm{H} 2-4 / \mathrm{H}-9 / \mathrm{H}-10 / \mathrm{H} 2-13 / \mathrm{H}-14$ was deduced from the above ${ }^{1} \mathrm{H}-{ }^{1} \mathrm{H}$ COSY analyses (Figure 6). HMBC correlation from Me-20 to carbonyl C-21 indicated that the carbonyl located at $\mathrm{C}-21$ and the formation of the amide with the help of the molecular formula information (Figure 6). HMBC cross peaks of Me-20/C-6, Me-20/C-7 and Me-20/C-21 positioned a methyl at C-7. HMBC cross peaks of Me-22/C-4, Me-22/C-5, Me-22/C-6 and Me-22/C-10 assigned a methyl group at C-5 and positioned a ketone group at C-6. HMBC correlations of H-9/C-5, H-9/C-7, H-9/C-10, H-9/C-18, H-10/C-5, H-10/C-6, H-10/C-9, H-10/C-11, H-10/C-18 and H-10/C-22, together with the HMBC cross peaks of Me-22/C-10 and Me-22/C-6 revealed that a rearranged polyketide fused ring structure was formed. The long range correlations of Me-17/C-3, H-4/C-12 and Me-17/C-11 connected the fused three rings with the seven membered olefinic ring. In the ${ }^{1} \mathrm{H}-\mathrm{NMR}$ spectrum of $\mathbf{1}$, seven methyl groups displayed six singlet signals (H-20 and H-25 were overlapped as one peak), one of which was assigned at olefinic quaternary C-2 from the observation of HMBC cross peaks of Me-23/C-1, Me-23/C-2 and Me-23/C-3. The long range correlation from the proton signal at $\delta_{\mathrm{H}} 3.67$ (s, Me-27) to the ester carbonyl signals at $\delta_{C} 137.2(\mathrm{C}-24)$ positioned the OMe attached at carbonyl 24. The HMBC correlations of H-14/C-16, H-25/C-15, H-13/C-15 and H-25/C-26 revealed that the lactone ring at the carbon backbone of berkeleyacetal A [13] was opened and rearranged, and a dimethyl carbinol group was attached at C-15. The quaternary carbon signal at $\delta_{C} 51.7$ was attributed to $C-11$ from the analysis of long range correlations from the proton signals at $\delta_{\mathrm{H}} 1.04(\mathrm{~s}, \mathrm{H}-17)$ to quaternary $\mathrm{C}-11$. The proton signals at $\delta_{\mathrm{H}} 3.28(\mathrm{~s}, \mathrm{H}-10)$ and $1.77(\mathrm{~s}, \mathrm{H}-13)$ also showed diagnostic HMBC correlations with $\delta_{\mathrm{C}} 51.7$. Considering the linkage with C-10, C-12 and C-18 and the chemical shift of quaternary carbon C-11, the amide bridge was formed between C-7 and C-11.

The main differences between the structures of $\mathbf{1}$ and the berkeleyacetals are the absence of the lactone ring and rearrangement of the bicyclic decahydrofuro[4,3,2-ij]isochromene moiety. In the structure of 1, the lactone ring at C-1 and C-15 was opened, with a dimethyl carbinol assigned at C-15 and a methoxycarbonyl group at C-1. The HMBC correlations between H-3 and C-2, C-3, C-4 and the long range correlations from Me-17 to C-11, C-12, and C-13 confirmed the linkage between the seven membered ring and three fused rings. By comparing NMR data with those of berkeleyacetal A 
in the literature [13], the three fused ring substructure was similar to that in berkeleyacetal A, however, the positions of the tetrahydropyran ring and tetrahydrofuran ring in the fused three ring substructure was rearranged as drawn in Figure 5. Diagnostic carbon signals of Me-22 $\left(\delta_{\mathrm{C}} 32.3\right)$, and the two methine proton signals at $\mathrm{H}-9\left(\delta_{\mathrm{H}} 6.09, \mathrm{~d}, J=7.1 \mathrm{~Hz}\right)$ and $\mathrm{H}-10\left(\delta_{\mathrm{H}} 3.28, \mathrm{~d}, J=7.1 \mathrm{~Hz}\right)$ appeared in the ${ }^{1} \mathrm{H}$ - and ${ }^{13} \mathrm{C}-\mathrm{NMR}$ spectra of $\mathbf{1}$. The HMBC cross peak of H-10/carbonyl C- 6 and the cross peak of H-9/C-18 confirmed that the three fused ring substructure was rearranged. Detailed two-dimensional NMR analysis permitted the assignment of the polycyclic hydrocarbon unit. Thus, the planar structure of $\mathbf{1}$ was elucidated as shown in Figure 5.

Table 1. NMR data for compound $1\left(600 \mathrm{MHz}, \mathrm{CD}_{3} \mathrm{OD}\right)$.

\begin{tabular}{|c|c|c|c|c|}
\hline Position & $\delta_{C} \mathrm{a}, \mathrm{b}$, Mult. & $\delta_{\mathrm{H}}{ }^{\mathrm{c}}$, Mult. $(J$ in $\mathrm{Hz})$ & НМВС & NOESY \\
\hline 1 & 127.9 & & & \\
\hline 2 & 139.8 & & & \\
\hline 3 & $44.8, \mathrm{CH}$ & 2.07, dd $(13.5,2.1)$ & $\mathrm{C}-1 / \mathrm{C}-2 / \mathrm{C}-12 / \mathrm{C}-17 / \mathrm{C}-23$ & $\mathrm{H}-4 \beta$ \\
\hline $4 \beta$ & $32.4, \mathrm{CH}_{2}$ & $1.49, \mathrm{t}(13.5)$ & $\mathrm{C}-3 / \mathrm{C}-5 / \mathrm{C}-6 / \mathrm{C}-12 / \mathrm{C}-22$ & $\mathrm{H}-4 \beta / \mathrm{H}-23 / \mathrm{H}-17 / \mathrm{H}-22$ \\
\hline $4 \alpha$ & & 2.39, dd $(13.6,2.6)$ & C-5/C-6/C-10/C-12 & $\mathrm{H}-4 \alpha / \mathrm{H}-22 / \mathrm{H}-3 / \mathrm{H}-23$ \\
\hline 5 & 48.0 & & & \\
\hline 6 & 211.2 & & & \\
\hline 7 & 81.8 & & & \\
\hline 8 & $\mathrm{O}$ & & & \\
\hline 9 & $100.0, \mathrm{CH}$ & $6.10, \mathrm{~d}(7.1)$ & C-5/C-7/C-10/C-18 & $\mathrm{H}-10$ \\
\hline 10 & $45.2, \mathrm{CH}$ & $3.27, \mathrm{~d}(7.1)$ & C-5/C-6/C-9/C-11/C-18/C-22 & H-9/H-17/H-22 \\
\hline 11 & 51.7 & & & \\
\hline 12 & 56.6 & & & \\
\hline $13 \alpha$ & $40.3, \mathrm{CH}_{2}$ & $2.51, \mathrm{dd}(13.2,8.0)$ & C-3/C-11/C-12/C-14/C-15 & $\mathrm{H}-13 \beta / \mathrm{H}-14$ \\
\hline $13 \beta$ & & 1.78, dd $(13.2,5.2)$ & C-11/C-12/C-14/C-15/C-17 & $\mathrm{H}-13 \alpha / \mathrm{H}-17$ \\
\hline 14 & $131.5, \mathrm{CH}$ & $6.40, \mathrm{dd}(8.0,5.2)$ & C-1/C-12/C-13/C-16 & $\mathrm{H}-25 / \mathrm{H}-13 \alpha$ \\
\hline 15 & 140.9 & & & \\
\hline 16 & 85.6 & & & \\
\hline 17 & $26.4, \mathrm{CH}_{3}$ & $1.04, \mathrm{~s}$ & C-3/C-11/C-12/C-13/C-14/C-18 & $\mathrm{H}-10 / \mathrm{H}-13 \beta / \mathrm{H}-4 \alpha$ \\
\hline 18 & 174.3 & & & \\
\hline 19 & $\mathrm{~N}$ & & & \\
\hline 20 & $26.8, \mathrm{CH}_{3}$ & $1.56, \mathrm{~s}$ & C-6/C-7/C-21 & H-22 \\
\hline 21 & 173.2 & & & \\
\hline 22 & $32.3, \mathrm{CH}_{3}$ & $1.40, \mathrm{~s}$ & C-4/C-5/C-6/C-10 & H- $10 / \mathrm{H}-20 / \mathrm{H}-4 \alpha / \mathrm{H}-4 \beta$ \\
\hline 23 & $16.5, \mathrm{CH}_{3}$ & $1.83, \mathrm{~s}$ & $C-1 / C-2 / C-3$ & $\mathrm{H}-4 \alpha / \mathrm{H}-4 \beta$ \\
\hline 24 & 173.2 & & & \\
\hline 25 & $27.8, \mathrm{CH}_{3}$ & $1.56, \mathrm{~s}$ & C-15/C-16/C-26 & $\mathrm{H}-14 / \mathrm{H}-26$ \\
\hline 26 & $30.7, \mathrm{CH}_{3}$ & $1.39, \mathrm{~s}$ & C-15/C-16/C-25 & H-25 \\
\hline 27 & $54.7, \mathrm{CH}_{3}$ & $3.67, \mathrm{~s}$ & C- 24 & \\
\hline
\end{tabular}
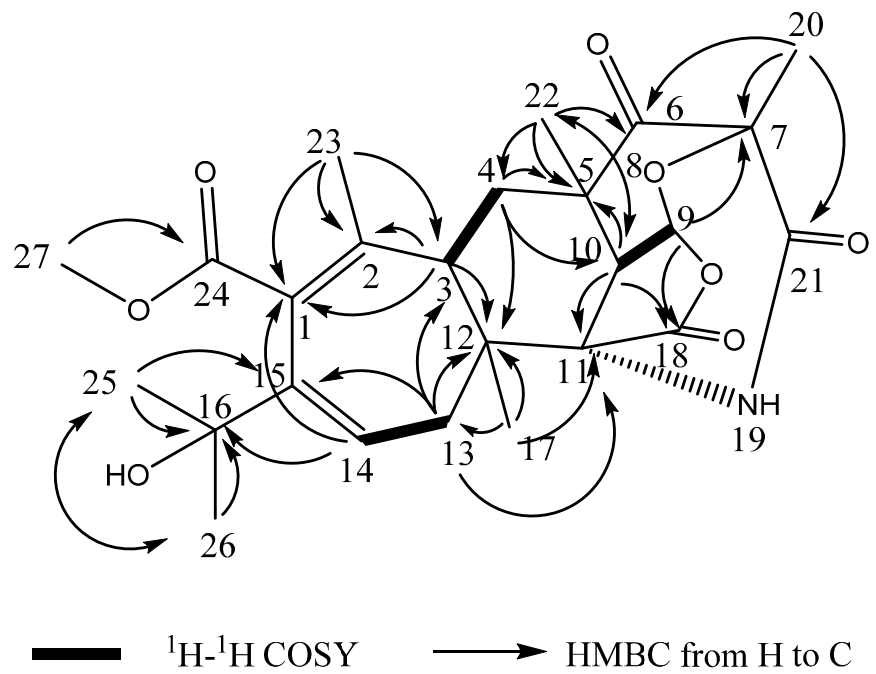

HMBC from $\mathrm{H}$ to $\mathrm{C}$

Figure 6. Key ${ }^{1} \mathrm{H}_{-}{ }^{1} \mathrm{H}$ COSY and $\mathrm{HMBC}$ correlations of compound $\mathbf{1}$. 
The relative configuration of compound 1 was determined by NOESY experiments. NOESY cross peaks of $\mathrm{H}-14 / \mathrm{H}-25, \mathrm{H}-17 / \mathrm{H}-10$ and $\mathrm{H}-10 / \mathrm{H}-22$ revealed a cyclohexyl chair ring with a $\beta$-oriented Me-17 at C-12 and a fused six membered pyrone boat ring with a $\beta$-oriented Me-20 at C-7 and a $\beta$-oriented Me-22 at C-5 (Figure 7). Since no NOESY correlation between H-3 and Me-17 was observed, the cyclohepta-1,3-diene ring and cyclohexane ring were trans-fused. H-10 showed NOESY cross peaks with $\mathrm{H}-9$, Me-17 and Me-22, indicating that pyran ring and tetrahydrofuran ring were cis-fused, and H-9 and H-10 were $\beta$-oriented. Thus, compound 1 was identified as a new compound and named aspergstressin.

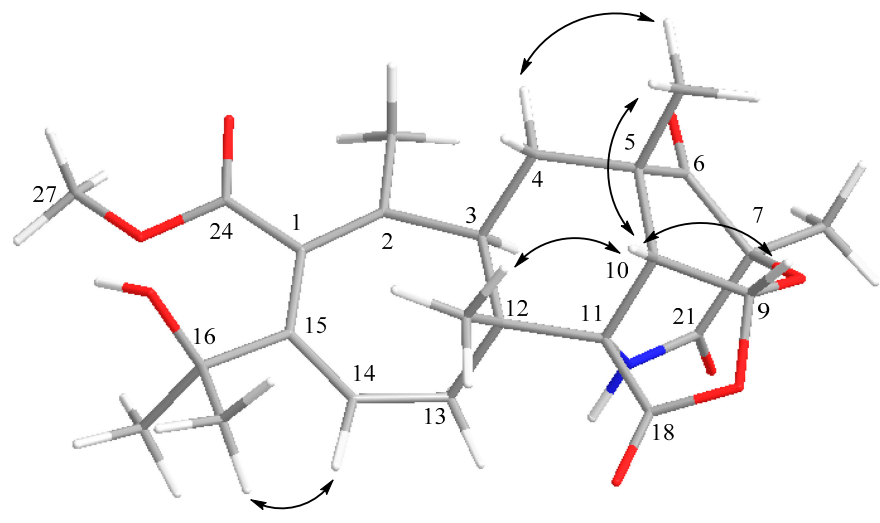

Figure 7. Key NOESY correlations of compound 1.

\subsection{Proposed Biosynthetic Pathway}

Berkeleyacetals, paraherquonin [14] and citreonigrin [15] are reported polyketide-terpenoids which have similar skeletons to aspergstressin. However, studies on their biosynthesis are scarce. Based on the biosynthetic studies on andibenin A-B [16] and terretonin [17], two other polyketide-terpenoid compounds isolated as Aspergillus fungal metabolites, a biosynthetic pathway can be proposed for the new stress-induced metabolite 1 (Scheme 1). Alkylation of 3,5-dimethylorsellinate by the terpenoid precursor farnesyl pyrophosphate gives the important intermediate 2. Polyketone ring opening and etherification with a hydroxyl forms an epoxy structure by enol tautomerism and oxidation (compound 3). Amidation at position 7 forms an amide bridge, followed by hydrolysis and rearrangement of the cyclohexene lactone ring to afford aspergstressin (1).

\section{Materials and Methods}

\subsection{General Procedures}

The high-performance liquid chromatography (HPLC) system used was composed of a Waters 717 plus Autosampler, a Waters 600 Controller, a Waters 996 Photodiode Array Detector and a Waters Millog workstation (Waters, Shinagawaku, Tokyo, Japan). Optical rotations were recorded on a 341 polarimeter (Perkin-Elmer, Shanghai, China). ${ }^{1} \mathrm{H}-\mathrm{NMR}(600 \mathrm{MHz})$ and ${ }^{13} \mathrm{C}-\mathrm{NMR}(150 \mathrm{MHz})$ spectra were measured at $25^{\circ} \mathrm{C}$ on an Agilent $600 \mathrm{MHz}$ DD2(DirectDrive2) spectrometer (Agilent, Beijing, China) with TMS as internal standard. ESIMS were recorded on a 6460 Triple Quad LC/MS (Agilent, Beijing, China). Prep. HPLC was performed on an Agilent-1100 system equipped with a Venusil MP-C18 column (10 mm) 250 mm (Agela Technologies, Shanghai, China). Sephadex LH-20 (Amersham, Piscataway, NJ, USA) was used for column chromatography. The organic solvents used in chromatographic separation were of analytical grade purchased from Sayfo Technology (Tianjin China) and chromatographic grade for HPLC analysis purchased from Tedia, USA. Deionized water was prepared by Reverse osmosis Milli-Q water (18 M $\Omega$ ) (Millipore, Bedford, MA, USA) and used for all solutions and dilutions. Agar powder for plate culture and cobalt chloride was purchased from Sinopharm Chemical Reagent Co., Ltd. (Shanghai, China). 


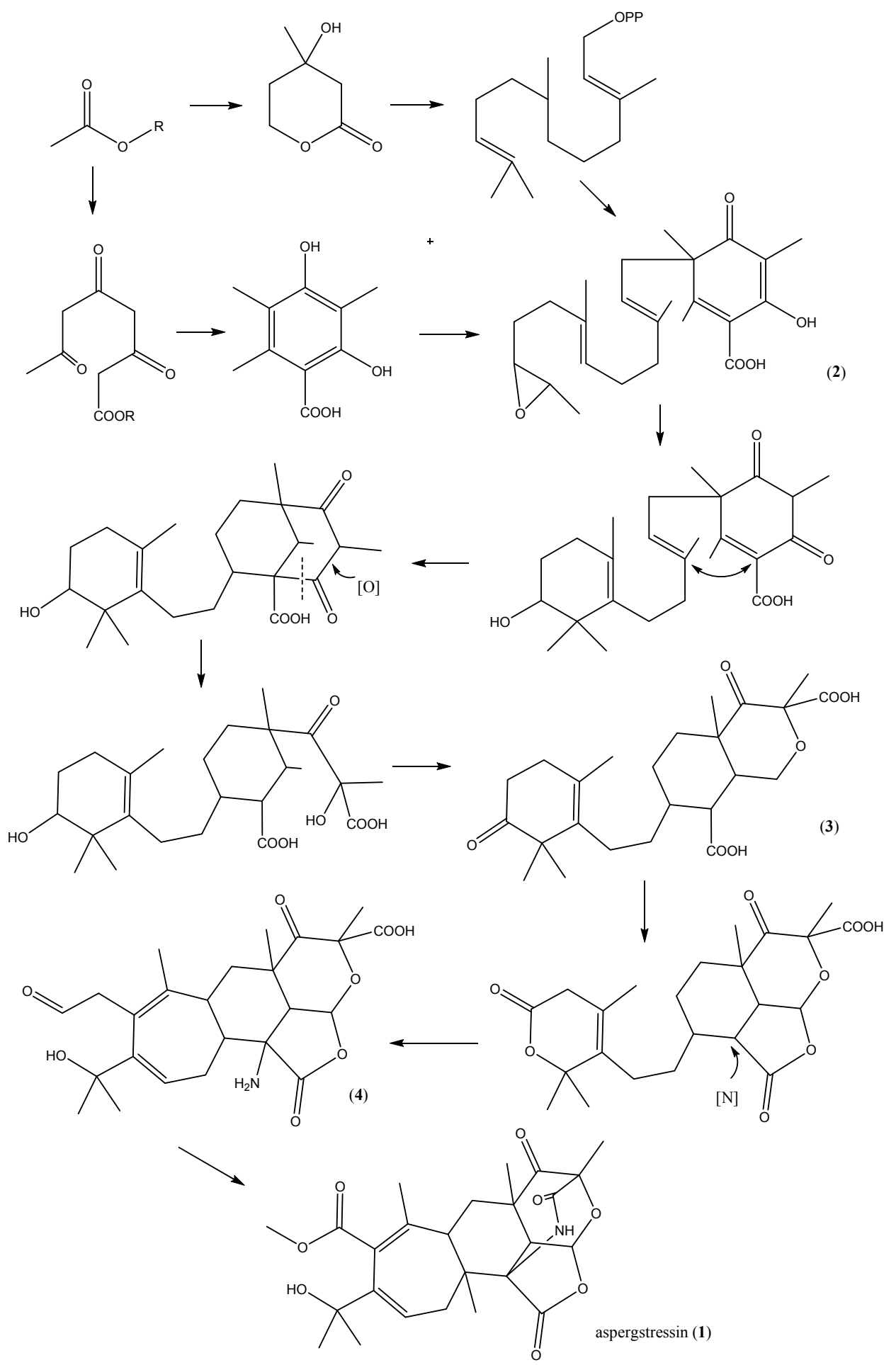

Scheme 1. Proposed biosynthetic pathway of compound 1.

\subsection{Isolation, Cultivation, and Storage of the Strain WU 243}

The strain WU 243 was isolated from the crab Xenograpsus testudinatus, which was collected from a Kueishantao hydrothermal vent (Taiwan). The strain was grown on PDA agar, consisting of $100 \mathrm{~g}$ potato lixivium, $10 \mathrm{~g}$ dextrose, $35 \mathrm{~g}$ sea salt and $15 \mathrm{~g}$ agar powder per litre. The strains were stored in $-80{ }^{\circ} \mathrm{C}$ cryopreservation box (Forma 700 Freezer, Thermo Scientific, Shanghai, China). 


\subsection{Normal Culture and Metal-Stress Cultivation}

Normal cultivation of strain WU 243 was carried out in $500 \mathrm{~mL}$ flasks containing $225 \mathrm{~mL}$ liquid PDB for 14 days at $24{ }^{\circ} \mathrm{C}$ as static cultures in the dark. To investigate the maximum inhibition concentration of cobalt ion and the optimal cultivation conditions, the metal-stress method was first scheduled with four cobalt ion concentrations of $0,5,10$ and $20 \mathrm{mM}$, respectively. The mycelium was removed and culture broth was extracted with an equal volume of ethyl acetate. Afterwards, the optimal stress conditions were investigated for more precise ion concentrations from $6 \mathrm{mM}$ to $10 \mathrm{mM}$. The final ion concentration for stress culture in large scale was determined as $6 \mathrm{mM}$ based on the HPLC profile of each extract and the peak areas of the stress-induced products.

\subsection{HPLC Analysis and Identification of Stress Metabolites}

Analytical reversed phase HPLC-UV experiments were performed using a $\mathrm{C}_{18}$ column (sepax Amethyst C18-H, $100 \mathrm{~mm} \times 3.00 \mathrm{~mm}$ ) applying an $\mathrm{H}_{2} \mathrm{O} /$ methanol $(\mathrm{MeOH})$ gradient from $20 \% \mathrm{MeOH}$ to $100 \% \mathrm{MeOH}$ in $30 \mathrm{~min}$, maintaining $100 \% \mathrm{MeOH}$ for $10 \mathrm{~min}$, flow rate $0.8 \mathrm{~mL} / \mathrm{min}$ on a LC20A system (Shimadzu, Kyoto, Japan) equipped with a Prominence CBM-20A/20 Alite controller, SPD-20A UV detector, and Prominence CTO-20A column oven. The stress-induced compounds were isolated by preparative HPLC, which was carried out using a HPLC-UV system (P3000 type high pressure infusion pump, UV3000 type ultraviolet/visible light detector, Rheodyne 7725 I manual sampling valve, sepax C18, $150 \mathrm{~mm} \times 80 \mathrm{~mm}$, column). Based on the results on analytical HPLC analysis, a constant mobile phase of $52 \% \mathrm{MeOH}$ for $30 \mathrm{~min}$ and a flow rate of $10 \mathrm{~mL} / \mathrm{min}$ were employed for isolation and purification of compound $\mathbf{1}$.

\subsection{Confirmation and Fermentation in Large Scale}

After defining the optimal cultivation conditions, the strain was cultivated under metal stress conditions in $500 \mathrm{~mL}$ of medium in triplicate. The broth was then extracted and the metabolite profiles were checked by HPLC to authenticate the viability of the stress method. Strain WU 243 was inoculated onto agar plates containing PDA medium. After incubation for 7 days at $24^{\circ} \mathrm{C}$, the pre-culture was used for inoculation of two $500 \mathrm{~mL}$ flasks containing $225 \mathrm{~mL}$ liquid medium (natural pH) as seed bottles. The seed bottles were incubated for 14 days a t $24{ }^{\circ} \mathrm{C}$ as static cultures in the dark. This broth was used as seed to amplify the culture scale. Five 5 L flasks which contained 2 L zymotic fluid and one hundred $500 \mathrm{~mL}$ flasks containing $200 \mathrm{~mL}$ liquid medium were used for large scale fermentation. A total of $20 \mathrm{~L}$ of broth containing $6 \mathrm{mM}$ cobalt ions was incubated for 18 days at $28^{\circ} \mathrm{C}$ as static cultures.

\subsection{Extraction and Isolation of Compound $\mathbf{1}$}

The $20 \mathrm{~L}$ of fermentation broth was extracted with ethyl acetate. After evaporation of the solvent the crude extract was dissolved in methanol. The extract was subjected to preparative HPLC (P3000 type high pressure infusion pump, UV3000 type ultraviolet/visible light detector, Rheodyne 7725 I manual sampling valve, sepax C18, $150 \mathrm{~mm} \times 80 \mathrm{~mm}$, column, flow rate $10 \mathrm{~mL} / \mathrm{min}, \mathrm{UV}$ detector $210 \mathrm{~nm})$, using $52 \% \mathrm{MeOH}$ as an eluent, to afford aspergstressin $\left(\mathbf{1}, 2.5 \mathrm{mg}, \mathrm{t}_{\mathrm{R}}=18.5 \mathrm{~min}\right)$; white powder; $[\alpha]_{\mathrm{D}}^{20}+274.24\left(c\right.$ 0.1, $\left.\mathrm{CH}_{3} \mathrm{OH}\right) ; \mathrm{UV}(\mathrm{MeOH}) \lambda_{\max }(\log \varepsilon) 203$ (2.13), 227.5 (1.85) nm; ${ }^{1} \mathrm{H}-\mathrm{NMR}$ and ${ }^{13} \mathrm{C}-\mathrm{NMR}$, see Table 1 ; ESIMS $m / z$ 474.2[M + H] ${ }^{+}$; HR-TOF-MS $m / z 474.2234[\mathrm{M}+\mathrm{H}]^{+}$ (calcd. For $\mathrm{C}_{25} \mathrm{H}_{31} \mathrm{NO}_{8}, 474.2122$ ).

\section{Conclusions}

The distribution of marine fungi is positively correlated to their host distribution [18]. Strain Aspergillus sp. WU 243 was isolated from Xenograpsus testudinatus, a crab residing around a heavy metal rich hydrothermal vents environment. Despite the fact that previous studies were carried out on the isolation of secondary metabolites from the widely distributed Aspergillus spp., as well as its 
metal adsorption characteristics [19-22], no studies have focused on the "metal stress" theory, here related to the heavy metal cobalt. Challenging microbes with toxic heavy metals has been proven to be an effective mean to stimulate their cryptic secondary metabolism [5-7]. In this study, a novel hybrid polyketide-terpenoid named aspergstressin (1), possessing a unique fused polycyclic structure, was induced by cobalt ion stimulation of culture broth of strain Aspergillus sp. WU 243. The result show that stress-driven discovery of new natural products from marine fungi is an effective strategy to unveil the untapped reservoir of small molecules produced by species living in the hydrothermal vent environment.

Supplementary Materials: Supplementary materials can be accessed at: http://www.mdpi.com/1420-3049/ $21 / 1 / 105 /$ s1.

Acknowledgments: This work was supported by NSFC (No. 81273386 and 81573306).

Author Contributions: The experimental work was designed and performed by C.D. under the supervision of B.W. who is the corresponding author. X.W. and K.W. contributed analysis tools. C.-T.A.C. and Y.Y. provided materials. C.D., B.N.A. and B.W. wrote the paper.

Conflicts of Interest: The authors declare no conflict of interest.

\section{References}

1. Holden, J.F.; Adams, M.W.W. Microbe-metal interactions in marine hydrothermal environments. Curr. Opin. Chem. Biol. 2003, 7, 160-165. [CrossRef]

2. Thornburg, C.C.; Zabriskie, T.M.; McPhail, K.L. Deep-sea hydrothermal vents: Potential hot spots for natural products discovery? J. Nat. Prod. 2010, 73, 489-499. [CrossRef] [PubMed]

3. Debbab, A.; Aly, A.H.; Lin, W.H.; Proksch, P. Bioactive compounds from marine bacteria and fungi. Microb. Biotechnol. 2010, 3, 544-563. [CrossRef] [PubMed]

4. Saleema, M.; Ali, M.S.; Hussain, S.; Jabbar, A.; Ashraf, M.; Lee, Y.S. Marine natural products of fungal origin. Nat. Prod. Rep. 2007, 24, 1142-1152. [CrossRef] [PubMed]

5. Wu, B.; Wu, X.; Sun, M.; Li, M. Two novel tyrosinase inhibitory sesquiterpenes induced by $\mathrm{CuCl}_{2}$ from a marine-derived fungus Pestalotiopsis sp. Z233. Mar. Drugs 2013, 11, 2713-2721. [CrossRef] [PubMed]

6. Jiang, W.; Zhong, Y.; Shen, L.; Wu, X.; Ye, Y.; Chen, C.T.A.; Wu, B. Stress-driven Discovery of Natural Products from Extreme Marine Environment-Kueishantao Hydrothermal Vent, a Case Study of Metal Switch Valve. Curr. Org. Chem. 2014, 18, 925-934. [CrossRef]

7. Haferburg, G.; Groth, I.; Möllmann, U.; Kothe, E.; Sattler, I. Arousing sleeping genes: Shifts in secondary metabolism of metal tolerant actinobacteria under conditions of heavy metal stress. Biometals 2009, 22, 225-234. [CrossRef] [PubMed]

8. Van den Brenk, A.L.; Fairlie, D.P.; Hanson, G.R.; Gahan, L.R.; Hawkins, C.J.; Jones, A. Binding of copper(II) to the cyclic octapeptide patellamide D. Inorg. Chem. 1994, 33, 2280-2289. [CrossRef]

9. Yang, J.X.; Qiu, S.X.; She, Z.G. Metabolites of Mangrove Endophytic Fungus Gx-3a from South China Sea. Technol. Dev. Chem. Ind. 2013, 2, 168-170.

10. Kimura, Y.; Tani, K.; Kojima, A. Cyclo-(L-tryptophyl-L-phenylalanyl), a plant growth regulator produced by the fungus Penicillium sp. Phytochemistry 1996, 41, 665-669. [CrossRef]

11. Taridaporn, B.; Seangaroon, Y.; Kamolphan, I. New Diphenyl Ethers from the Insect Pathogenic Fungus Cordyceps sp. BCC 1861. Chem. Pharm. Bull. 2007, 55, 304-307.

12. Zheng, C.J.; Shao, C.L.; Wang, K.L. Secondary metabolites and their bioactivities of a soft coral-derived fungus Aspergillus versicolor(ZJ-2008015). Chin. J. Mar. Drugs 2012, 31, 7-13.

13. Stierle, D.B.; Stierle, A.A.; Patacini, B. The Berkeleyacetals, three meroterpenes from a deep water Acid mine waste Penicillium. J. Nat. Prod. 2007, 70, 1820-1823. [CrossRef] [PubMed]

14. Okuyama, E.; Yamazaki, M.; Kobayashi, K.; Sakurai, T. Paraherquonin, a new meroterpenoid from penicillium paraherquei. Tetraheadron Lett. 1983, 24, 3113-3114. [CrossRef]

15. Ebel, R.; Rusman, Y.; Brauers, G.; Proksch, P.; Frank, W.; Wray, V. Abstracts of the 54th Annual Congress on Medicinal Plant Research, 29 August-2 September 2006, Helsinki, Finland. Planta Med. 2006, 72, 961-1083. 
16. Simpson, T.J.; Ahmed, S.A.; Mcintyre, C.R.; Scott, F.E.; Sadler, I.H. Biosynthesis of polyketide-terpenoid (meroterpenoid) metabolites andibenin $\mathrm{b}$ and andilesin a in aspergillus variecolor. Tetrahedron 1997, 53, 4013-4034. [CrossRef]

17. Mcintyre, C.R.; Simpson, T.J. Biosynthesis of terretonin, a polyketide-terpenoid metabolite of aspergillus terreus. J. Chem. Soci. Chem. Commun. 1981, 20, 1043-1044. [CrossRef]

18. Aleem, A.A. Distribution and ecology of marine fungi in Sierra Leone (tropical West Africa). Bota Mari 1980, 23, 679-688.

19. Fang, F.; Ui, H.; Shiomi, K.; Masuma, R.; Yamaguchi, Y.; Zhang, C.G. Two new components of the aspochalasins produced by Aspergillus sp. J. Antibiot. 1995, 11, 919-925. [CrossRef]

20. Hanson, F.R.; Eble, T.E. An antiphage agent isolated from aspergillus sp. J. Bacteriol. 1949, 4, 527-529.

21. Iqbal, A.; Mohd, A.; Farrukh, A. Biosorption of $\mathrm{Ni}, \mathrm{Cr}$ and $\mathrm{Cd}$ by metal tolerant Aspergillus niger and penicillium sp. using single and multi-metal solution. India J. Exp. Biol. 2006, 44, 73-76.

22. Shi, Y.; Wei, J.; Auckloo, B.N.; Wu, B. Wu, B. Several Classes of Natural Products with Metal ion Chelating Ability. Curr. Org. Chem. 2015, 19, 1935-1953. [CrossRef]

Sample Availability: Sample of the compound 1 is available from the authors.

(C) 2016 by the authors; licensee MDPI, Basel, Switzerland. This article is an open access article distributed under the terms and conditions of the Creative Commons by Attribution (CC-BY) license (http:/ / creativecommons.org/licenses/by/4.0/). 